\title{
Epidemiological Transition and the Double Burden of Disease in Accra, Ghana
}

\author{
Samuel Agyei-Mensah and Ama de-Graft Aikins
}

\begin{abstract}
It has long been recognized that as societies modernize, they experience significant changes in their patterns of health and disease. Despite rapid modernization across the globe, there are relatively few detailed case studies of changes in health and disease within specific countries especially for sub-Saharan African countries. This paper presents evidence to illustrate the nature and speed of the epidemiological transition in Accra, Ghana's capital city. As the most urbanized and modernized Ghanaian city, and as the national center of multidisciplinary research since becoming state capital in 1877, Accra constitutes an important case study for understanding the epidemiological transition in African cities. We review multidisciplinary research on culture, development, health, and disease in Accra since the late nineteenth century, as well as relevant work on Ghana's socio-economic and demographic changes and burden of chronic disease. Our review indicates that the epidemiological transition in Accra reflects a protracted polarized model. A "protracted" double burden of infectious and chronic disease constitutes major causes of morbidity and mortality. This double burden is polarized across social class. While wealthy communities experience higher risk of chronic diseases, poor communities experience higher risk of infectious diseases and a double burden of infectious and chronic diseases. Urbanization, urban poverty and globalization are key factors in the transition. We explore the structures and processes of these factors and consider the implications for the epidemiological transition in other African cities.
\end{abstract}

KEYWORDS Infectious diseases, Chronic noncommunicable diseases, Epidemiological transition, Migration, Urbanization, Urban poverty, Globalization, Accra

\section{INTRODUCTION}

It has long been recognized that as societies modernize, they experience significant changes in their patterns of health and disease. ${ }^{1}$ Despite rapid modernization across the globe, there are relatively few detailed case studies of changes in health and disease within specific countries, especially for sub-Saharan African countries. This paper examines epidemiological change in Accra, Ghana's capital.

As the colonial capital after relocation from Cape Coast in 1877, Accra has always occupied a central place in the literature on Ghanaian culture, development, and health, particularly during the colonial period. A wealth of information on health and disease in Accra has been produced by medical historians such as Patterson ${ }^{2}$ and

\footnotetext{
Agyei-Mensah is with the Department of Geography and Resource Development, University of Ghana, Legon, Ghana; de-Graft Aikins is with the Department of Social and Developmental Psychology, University of Cambridge, Cambridge, UK; de-Graft Aikins is with the Regional Institute for Population Studies, University of Ghana, Legon, Ghana.

Correspondence: Samuel Agyei-Mensah, Phd, Department of Geography and Resource Development, University of Ghana, Legon, Ghana. (E-mail: samensah@ug.edu.gh)
} 
Addae ${ }^{3}$ medical scientists such as Pobee; ${ }^{4}$ sociologists and anthropologists such as Field, ${ }^{5}$ Acquah, ${ }^{6}$ and Robertson; ${ }^{7}$ and recent multi-institutional medical and public health collaborations such as the London School of Hygiene and Tropical Medicine and the Health Research Unit of Ghana's Health Service, ${ }^{8}$ the Stockholm Environmental Institute and the Department of Geography Legon, ${ }^{9}$ and the schools of public health at Harvard University and the University of Ghana. ${ }^{10}$ This information remains to be synthesized in ways that illuminate epidemiological trends in Accra over a theoretically significant period of time (e.g., pre- and postcolonial eras).

In this paper we begin the process of synthesizing insights from these existing studies, as well as from relevant work on Ghana's socio-demographic and epidemiological transition and the burden of chronic disease. A central argument we develop in this paper is that Accra's epidemiological transition requires a longitudinal and integrated treatment of macro- and microsocial processes, an approach that situates recent complex changes within their historical context. We begin this process by describing the evolution of Accra from a colonial town to a modern global city and the health changes it has endured through intricately connected demographic, economic, sociocultural, and geopolitical processes. This preliminary description and analysis of broad trends attempts to set the scene for deeper empirically driven analysis of the causes and consequences of the epidemiological changes for specific communities and their implications for Accra's future health status. It also provides potential insights for understanding the epidemiological transition in other African cities.

\section{MODELS OF EPIDEMIOLOGICAL CHANGE}

The epidemiological transition model developed by Omran "focuses on the complex changes in patterns of health and disease, the interactions between these patterns, and their demographic, economic, and sociologic determinants and consequences." 1 In its original form, the model proposed three stages of epidemiological transition. The first stage, referred to as the "Age of Pestilence and Famine," was characterized by a demographic regime of high and fluctuating birth and death rates that reflected Old World epidemics of infection and famine. At this stage, high death rates kept population growth to a minimum. The second stage was the "Age of Receding Pandemics," in which epidemics became less frequent and the impact of infectious disease on death rates declined. The third stage of the transition constituted the "Age of Degenerative and Man-made Diseases." This stage of transition was largely driven by social factors such as lifestyle, diet, occupation, and income. Omran argued that as infectious and parasitic diseases receded, their place would be taken by a series of chronic, degenerative diseases associated with ageing populations, such as cardiovascular disease, stroke, and cancers: these diseases would become significant causes of mortality. More recently, two additional stages have been added to Omran's model. ${ }^{11,12}$ Thus a fourth stage constitutes the "Age of Delayed Degenerative Diseases": here, degenerative diseases such as cardiovascular diseases and cancers still remain important as major causes of death, but changes in medical technology lengthen the life expectancy of elderly people suffering from cancer and cardiovascular disease. The fifth stage referred to as the 'Age of Emergent and Reemergent Infections ${ }^{, 12}$ is characterized by the resurgence of both old and new infectious and parasitic diseases. The stages proposed in Omran's original and revised models occur sequentially.

Omran's model has been adopted in numerous geographic and health-related studies. ${ }^{13-15}$ With rare exceptions, such as references in the edited volume of 
Jamison et al. $^{16}$ on disease and mortality in sub-Saharan Africa, there has been limited application of the model to the African context. While widely used, Omran's model has not escaped critique. A dominant critique focuses on the fact that the sequential stage process proposed by the model does not reflect epidemiological changes in some societies. For example, in an assessment of the epidemiological transition in Latin America, Frenk et al. $^{13}$ concluded that the Latin American experience does not fit the model because of the resurgence of malaria and dengue fever in the region, as well as rising differences in the two broad disease categories (infectious vs. chronic degenerative) between regions and social classes. Frenk et al. ${ }^{13}$ conceptualized the protracted polarized model to describe the Latin American transition. This model had two key elements. The "prolonged or protracted" element described partial changes in morbidity and mortality patterns that resulted in the coexistence of infectious disease (both a resurgence of the old and the emergence of the new) and chronic noncommunicable diseases. The "epidemiological polarized" element described the relationship between social class inequalities and higher morbidity and mortality rates among poor populations who experience higher rates of infectious and nutrition-related diseases. This model is strongly aligned with current discussions on Africa's “double burden of disease" which recognize the coexistence of communicable diseases such as malaria and tuberculosis, and chronic noncommunicable diseases such as hypertension, stroke, and diabetes. ${ }^{17,18}$ Crucially, researchers underscore the relationship between poverty and Africa's rising burden of chronic disease. A key factor is the role of comorbidities: major infectious diseases of poverty increase the risk of chronic diseases. Tuberculosis has been linked to diabetes, and antiretroviral treatment (ART) for HIV and AIDS have been linked to metabolic complications leading to cardiovascular diseases and diabetes. ${ }^{19,20}$ The impact of comorbidities on the cumulative burden of infectious and chronic diseases is likely to be strongest in African cities that are experiencing high levels of rural-urban migration, urbanization, and urban poverty. This makes the protracted polarized model a useful conceptual framework to examine the epidemiological transition in African cities. As Smallman-Raynor and Phillips ${ }^{12}$ observe, the key elements of the model "are evident in the large cities of some developing countries," where "the richer sections of the population may develop more or less 'modern' health and disease profiles whilst some poorer sectors may experience the double jeopardy of infectious and chronic/degenerative ailments." One rare, but pertinent, African case study of epidemiological transition conducted by Kahn et al. ${ }^{21}$ suggests that the model may also be appropriate for examining epidemiological trends in rural Africa. Kahn et al. ${ }^{21}$ examined trends in age-specific mortality in a rural South African population and reported a "counter transition" of increasing mortality among children and young adults, an "epidemiologic polarization" of a higher mortality burden among vulnerable, poor groups, and a "protracted transition" with a coexistence of HIV/AIDS and chronic diseases in older adults.

In our description and preliminary analysis of epidemiological changes in Accra, we draw on the protracted polarized model by Frenk et al. ${ }^{13}$ We aim to demonstrate that Accra's epidemiological changes are a product of complex, dynamic macro- and microsocial processes and that the stages change, and rather than proceeding in a sequential manner, have overlapped over a significant period. We also aim to describe the causes and course of the double burden of disease in Accra, which underscore the existence of both elements of the model, with the cumulative impact of infectious and chronic diseases intensified by wide disparities in socioeconomic status. 


\section{ACCRA IN TRANSITION, 1877-2007}

Accra is the capital of Ghana and is located in the Greater Accra Region, the most among the country's ten administrative regions. Geographically, Accra is bounded on the north by latitude $541.4 \mathrm{~N}$, on the south by the Gulf of Guinea, on the east by Longitude $0001 \mathrm{E}$ and on the west by Longitude 0021.5 (see Figure 1). It covers an area of about $420 \mathrm{~km}^{2}$. With an estimated population of 1.7 million in 2000, Accra contains $70 \%$ of the total population of Greater Accra Region, accounts for $30 \%$ of the urban population of Ghana, and accounts for $10 \%$ of the total population of Ghana.

\section{Colonial Accra, 1877-1957}

Socio-Economic and Demographic Changes Historians note that the Accra plains featured a vibrant traditional economy inhabited by Le and Kpeshie peoples as early as the thirteenth century. ${ }^{22}$ These earliest known settlers were absorbed by Gas who, different historical versions claim, either migrated to Accra in the thirteenth century from ancient Israel, through Egypt and Nigeria, or arrived in Accra in the sixteenth century from much closer origins in Benin or Ife. ${ }^{22}$ Like other coastal areas of the then Gold Coast, Accra became host and facilitator to European commercial activities, including the slave trade. About eight of the Gold Coast's sixty former European castles, forts and lodges were located along the Accra coast: Christianborg castle, "James and Ussher Forts, and five unnamed Dutch, Danish, and Portuguese lodges. ${ }^{23}$ The sixteenth and seventeenth centuries saw rapid population growth of Ga towns and their transformation into urban centers by the mid-seventeenth century. ${ }^{24}$ Well-known areas in Accra today, such as La, Teshie, Abossey Okai, and Mamprobi, were then popular markets for livestock, fish, and general goods. The early half of the nineteenth century deepened Accra's growing status as a trading center. Geopolitical factors also contributed to Accra's growth during this period. For example, historians document the immigration-and deportation, after the failed "Revolt of the Males"—of freed Africans and slaves from Brazil to Accra and other West African towns such as Ouidah, Badagry and Lagos in the 1820s and 1830 s. $^{25}$ In 1877, Accra became the administrative capital of the Gold Coast, taking over from Cape Coast. Socioeconomic and infrastructural developments led to increased immigration of people from other parts of the Gold Coast, as well as from French West Africa, Liberia, Nigeria, and Sierra Leone. These developments led to a change in the population structure of Accra, from a Ga-dominated town to an urban complex consisting of many indigenous ethnic groups and foreign migrants. The population structure was also affected by health crises in the late nineteenth and early twentieth centuries. The crises included a devastating fire in 1894, an earthquake in 1906, the bubonic plague in 1908 and the influenza epidemic of 1918-1919. ${ }^{7}$ The plague in 1908 killed 127 people in the city. The devastation caused by the plague exposed the extent of the city's underdevelopment. Accra Town Council was declared a failure in its role as a sanitation board by an independent inquiry led by W. J. R. Simpson. Simpson's report aimed to investigate the conditions that had given rise to an outbreak of plague in the Gold Coast and to

\footnotetext{
"Now the seat of government.
} 


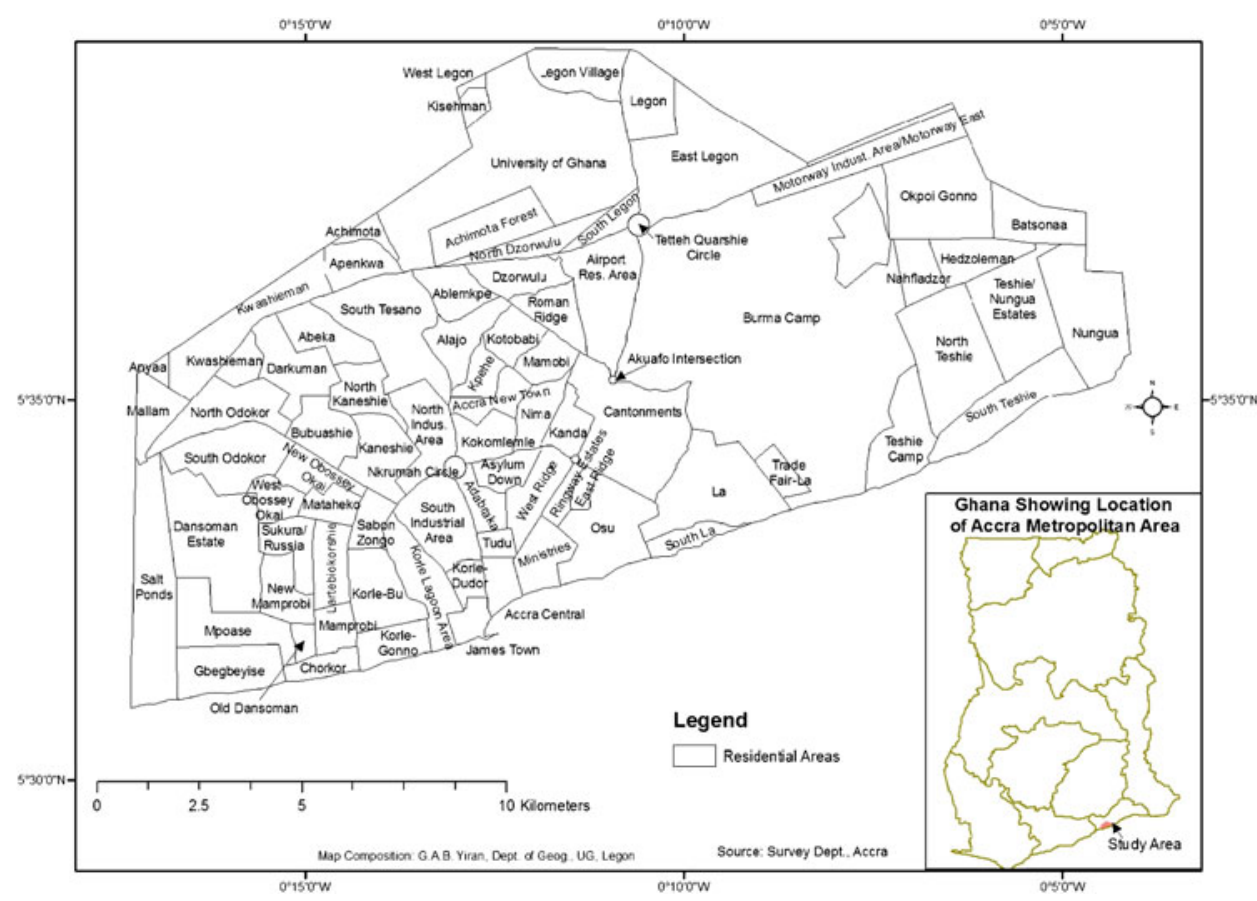

FIGURE 1. Map of Accra.

report on the general sanitary conditions. ${ }^{26}$ The measures taken after its publication led to the first serious efforts to improve health conditions for all inhabitants. ${ }^{2}$

Accra's population continued to grow. From 18,574 in 1911, Accra's population rose to 38,049 in 1921, to 61,558 in 1931, and by 1948 - the defining period of the Gold Coast's independence struggles-the population was 135,926. Population increase led to the gradual expansion of the city's administrative boundaries in the 1930s. The Ga community gradually lost majority status after this period. In 1948, the Ga constituted $51.6 \%$ of the population of Accra; by 1960, it constituted $37.5 \%$ of the population. ${ }^{27}$ The first plan for Accra was prepared in 1944. This plan was revised twice: in 1958 and in 1961. These plans provided for a spacious city with well-defined roads and public services at a standard in keeping with the expectations of a city at the time. However, the plans did not anticipate a rapid increase in population. ${ }^{28}$

World War II and its aftermath had a major impact on the demography of Accra. It brought a large influx of immigrants into the city from other parts of the country and from the African continent. New urban settlements were created for the rising population. These included Nima, Accra New Town, Asylum Down, Tesano and Odorkor (see Figure 1). Between 1948 and 1960, the population of Accra increased almost 3-fold from 135,926 to 364,719 (see Figure 2). ${ }^{7}$

Public Health Before the plague of 1908 and the publication of the Simpson Report, some attention had been paid to public health and medical services. Pipeborne water was one of the colonial government's major contributions to public health in Accra. In 1904, the construction of the Accra waterworks began at Weija (15 km west of Accra): this was completed in $1914 .^{7}$ People had earlier depended on rainwater from rooftop storage tanks or on water from polluted wells. The introduction of pipe-borne water helped reduce the incidence of many water-borne diseases such as guinea worm, typhoid fever, and dysentery. ${ }^{2}$ 


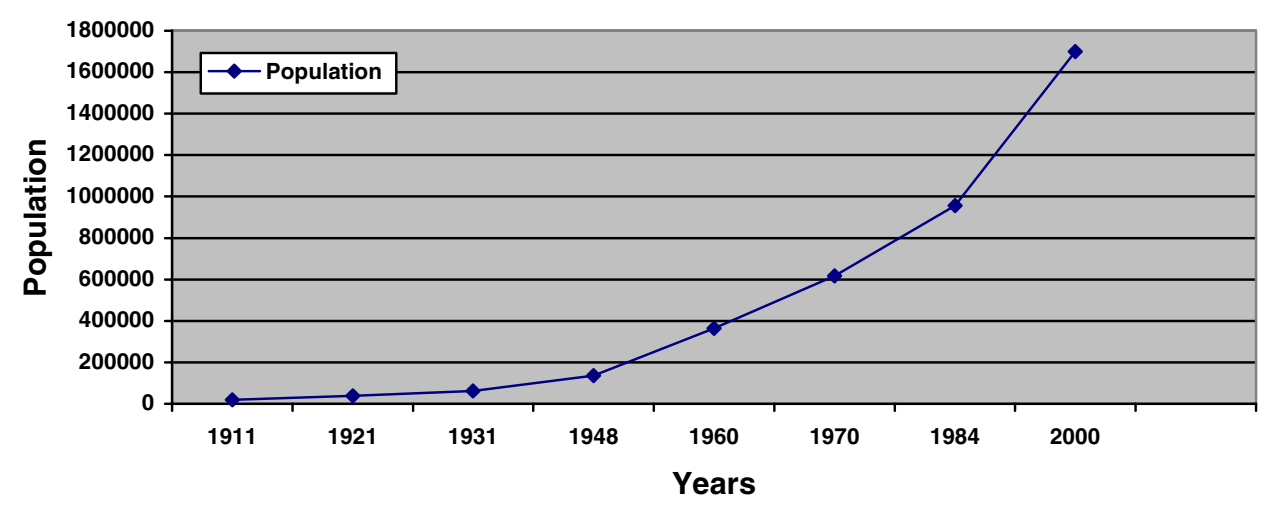

FIGURE 2. Population change in Accra, 1911-2000.

Expansion of health services also contributed indirectly to public health improvements. In 1882, Accra Hospital was built: it had 40 to 46 beds for Africans and a smaller number of beds for Europeans. In 1916, a European hospital-now called Ridge Hospital-was built in the Ridge Area, an exclusively European residential area. In 1924, the Gold Coast Hospital-now the Korle Bu Teaching Hospital-was completed at Korle $\mathrm{Bu}$, a suburb of Accra. Its initial capacity was for 96 patients. The 1920s generally saw sweeping changes to public policies initiated by the governor of the period, Sir Gordon Guggisberg. Guggisberg produced the first 10-year development plan, launched in 1924 to improve health, educational, and economic development across the colony. Part of this plan included a policy statement, issued in 1927, to ensure the treatment of both natives of Gold Coast and the Europeans. Before this period, significant attention was paid to the health of the minority European population with comparative neglect of the health of the people of Gold Coast. ${ }^{3}$ This public health strategy was dominant across colonized West African cities such as Freetown (Sierra Leone) and Banjul (The Gambia). ${ }^{29}$ The 1930s depression and World War II affected the quality of health services. The health budget and public service spending were reduced significantly as British finances were diverted to tackle these global crises.

The coexistence of infectious communicable diseases and chronic noncommunicable diseases had been recorded at Korle Bu as early as the 1920s with stroke cases assuming importance as causes of disability and death. ${ }^{4}$ Medical doctors also observed the interrelationship between infections and chronic diseases. For example, chronic heart disease was linked to common infections. ${ }^{4}$ Records on causes of death in the 1950s showed the coexistence of both infectious communicable diseases and chronic noncommunicable diseases as causes of death. Acquah's ${ }^{6}$ social survey of Accra in the 1950s revealed that infectious and parasitic diseases were the major causes of death, followed by diseases of (2) infancy, (3) respiratory systems, (4) digestive systems, (5) nervous systems, (6) old age, (7) circulatory systems, (8) pregnancy, and (9) injuries resulting from violence (see Table 1). ${ }^{8,30}$ Available mortality statistics for the period indicate that mortality rates were relatively high at the turn of the twentieth century, but decreased in the decades that followed (see Figure 3). In 1910, the crude death rate was estimated at 50 per 1000 of the total population; by 1930, the death rate had reduced to 21 deaths per 1000; a further reduction to 18.1 per 1000 was recorded in 1945 . The reductions in mortality were due largely to improvements in public health, education, and nutrition. ${ }^{2}$ 


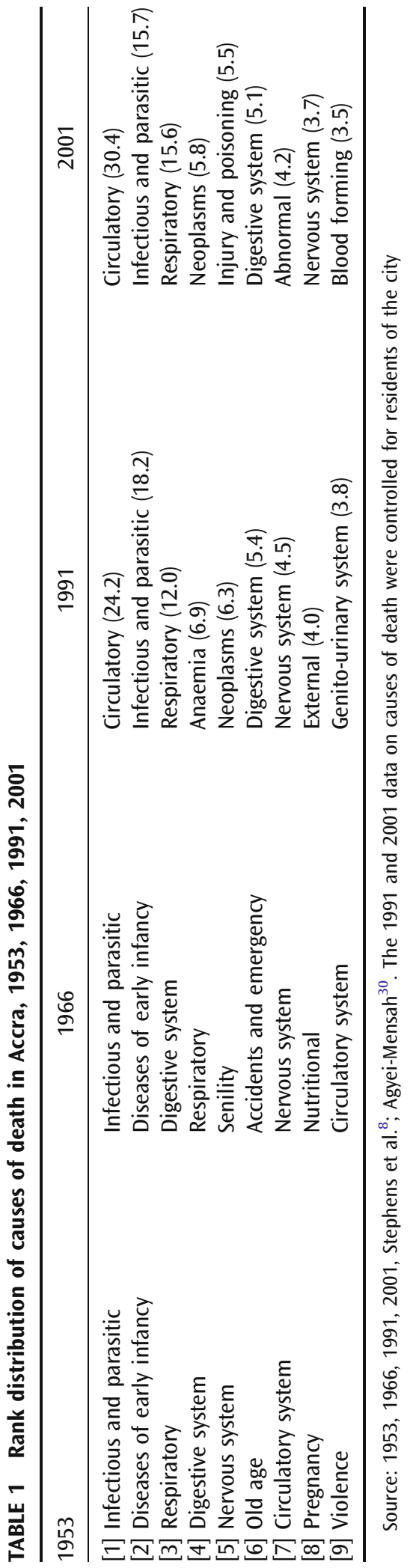




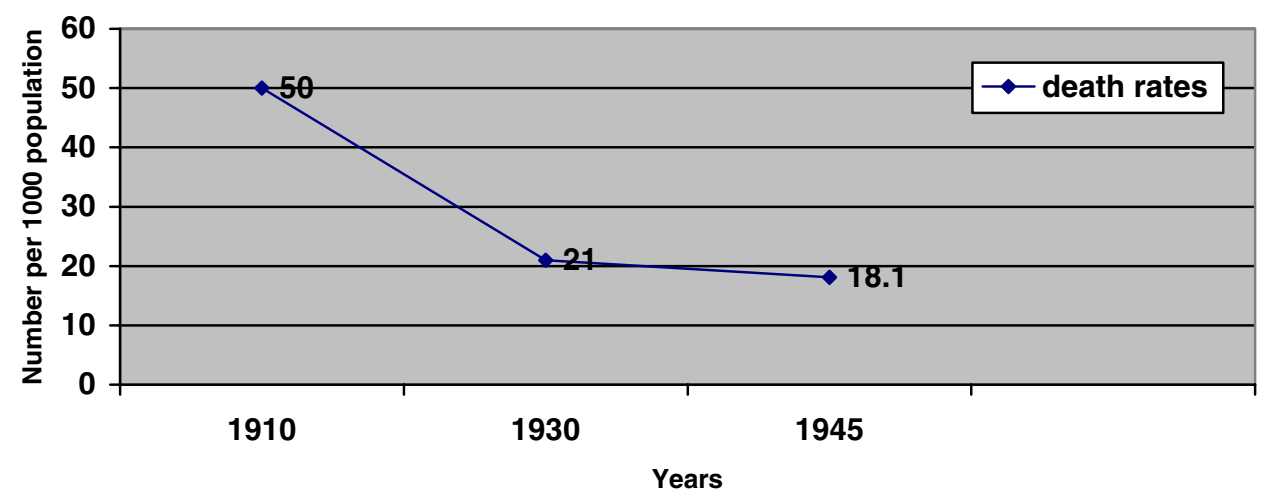

FIGURE 3. Death rates in Accra, 1910-1945.

\section{Post-Independence Accra, 1957-1982}

Socio-Economic and Demographic Changes In the decade following independence, Accra's position as an industrial, administrative, and industrial center grew, and the city attracted large numbers of people who came in search of jobs and to experience urban life. Geopolitical factors also contributed to Accra's status as an increasingly cosmopolitan city. Ghana's status as the first black, sub-Saharan African country to gain political independence, coupled with (first president) Kwame Nkrumah's panAfricanist project attracted a considerable number of Africans, African Americans, and Caribbeans to the country and to Accra in particular. ${ }^{25}$ Accra's population grew at an annual rate of 5.1\% between $1960(364,719)$ and $1970(617,415)$ and $3.1 \%$ between 1970 and 1984 (956,157) (see Figure 2).

Accra's increasing population created severe housing shortages. According to the 1960 census of Ghana, $60 \%$ of the urban population lived with three or more persons per room while $40 \%$ lived with four or five persons per room. In the case of Accra, about $60 \%$ of the population lived with four persons per room. Housing shortages and increased overcrowding in limited spaces had clear implications on sanitation and health.

Public Health and the Burden of Disease At independence, Ghana inherited the colonial health infrastructure that was mainly curative and a public health approach that was limited to control of major outbreaks of epidemic diseases such as smallpox and yellow fever. ${ }^{3}$ The wealthy socialist regime of Kwame Nkrumah aimed to accelerate the pace of socioeconomic development even further and to improve the general welfare of Ghanaians. Health and education became centerpieces of state reforms. Investments made in public health promoted sweeping changes in health policy and administration. The University of Ghana Medical School was established in 1962 to train more Ghanaian doctors on home soil. Several government polyclinics were established and there was widespread growth in the private medical industry. Health care became virtually free for all segments of Ghanaian society. As the capital, Accra benefited from these state initiatives.

The public health approach was still limited to prevention of communicable diseases. Efforts were made to improve infrastructural services and to eradicate endemic and epidemic diseases. Major water supply schemes were established at Kpong dam/water works (80 km east of Accra) and at Weija Dam/waterworks to provide water services to the city. These had long-term benefits to health standards 
in the city. Immunization programs were implemented. In 1977, the Ghana Health Assessment Project ranked measles second to malaria in terms of the burden of disease. ${ }^{31}$ Measles vaccine was introduced to selected districts in Ghana as part of the Expanded Program on Immunization in 1978. After a major epidemic involving 64,557 reported cases in 1985, a mass measles vaccination campaign was organized targeting children below the age of five.

Hospital-based and community-based studies on chronic noncommunicable diseases in Ghana increased during the 1950s and 1960s. ${ }^{32}$ This body of work revealed an increasing burden of chronic noncommunicable diseases in Accra. In the 1960 s, $35 \%$ of cases presented at the Korle Bu Hospital were due to hypertension. ${ }^{33}$ Between 1960 and 1968, strokes accounted for 8\% of medical admissions and 6$10 \%$ of adult deaths at Korle $\mathrm{Bu}$; hypertension, diabetes, and obesity constituted important associated factors. ${ }^{34}$ By 1972 , strokes constituted $10.4 \%$ of all medical admissions and $21.4 \%$ of all deaths. Female admissions and deaths $(8.6 \%$ and $24.6 \%$, respectively) far outnumbered male admissions and deaths $(1.8 \%$ and $20 \%$, respectively). Cancer cases presented at the hospital-especially breast and cervical cancer-also increased during this period. ${ }^{35,36}$

A World Health Organization community-based study begun at Mamprobi, a suburb of Accra, in the 1970s. This study provided the first documented evidence on community-based, cardiovascular prevalence rates and predisposing factors. The study researchers recorded hypertension prevalence of $13 \%$ in the community. Two further important trends were recorded. Infections were a common cause of death in the younger age group, while noncommunicable chronic diseases were commoner in the older age group. Infections were twice more likely to cause death in low-income groups than in the middle- and high-income groups; noncommunicable chronic diseases were four times more likely to cause death in the middle- and high-income groups compared to the low-income groups. ${ }^{4}$

Miltenyi's (1967) work (cited in Stephens et al.) ${ }^{8}$ provides information on causes of death during the 1960s. Infectious and parasitic diseases were ranked as top causes of death, followed by diseases of (2) early infancy, (3) digestive system, (4) respiratory system, (5) senility, (6) injuries caused through accidents and violence, (7) the nervous system, (8) nutrition, and (9) circulatory diseases (see Table 1). It is worth noting that the two top causes of death in the 1960s were identical to Acquah's $(1972)^{6}$ reported top two causes of death in the early 1950 s and also that circulatory diseases remained significant causes of death.

\section{Post-Adjustment Accra, 1983-2007}

Socio-Economic and Demographic Changes 1970s Accra experienced a general economic decline similar to other African cities such as Lagos and Freetown. The decline was attributed to the depressed state of the international economy and declining earnings from the commodity and export markets. ${ }^{37}$ This period also ushered in the era of military rule and of political instability. Between 1972 and 1982, Ghana had no fewer than six governments; " with the exception of one, they

\footnotetext{
*The governments were the National Redemption Council (1972-1975), the Supreme Military council I (1976-1978), the Supreme Military Council II (1978-1979), the Armed Forces Defence Council (JuneSeptember 1989), Peoples National Party (1979-81), and the Provisional National Defence Council (PNDC; 1982-1992).
} 
were all military governments that came into power through coup d'etats. Addae ${ }^{3}$ notes that the period of political instability was "disastrous" for medical services because successive governments "lost their ability to maintain, improve, or expand public health institutions and physical facilities." This period also led to widespread developmental crises, as Konadu-Agyemang ${ }^{37}$ acutely describes:

Between 1970 and 1983, import volumes declined by over 33\%, real export earnings fell by $52 \%$ while domestic savings and investments dropped from $12 \%$ of GDP to almost zero, and an unprecedented number of Ghanaians-artisans, teachers, and medical professional, as well as the unskilled-left the country. By the early 1980s, the inflation rate was in excess of $100 \%$, the per capita GDP had fallen from its 1960 level of US $\$ 1009$ to $\$ 739$, and the nation was going through one of the worst droughts and famines in its history. As if these troubles were not enough, the Nigerian government suddenly repatriated well over one million Ghanaians whose arrival worsened the already chaotic socioeconomic environment.

The PNDC government invited the International Monetary Fund (IMF) and the World Bank to provide solutions for the crises. The IMF and World Bank proposed Structural Adjustment Programs (SAPs).

These were identical to IMF and World Bank programs for other third world countries. They constituted "a package of actions that included currency devaluation, reducing inflation, downsizing the public service, drastic cutbacks on government expenditure on education, health and welfare, financial reforms, privatization of public enterprises, export promotion, and other policies geared to enhancing economic growth." 37

At the macro level, the SAPs are reported to have "rescued Ghana's economy from complete collapse." 37 For example, Ghana's negative GDP growth of the 1970 s was reversed, inflation dropped from $123 \%$ in the early 1980 s to $32 \%$ in 1991, and pre-1980s ailing industries improved their production capacity to between $35 \%$ and $40 \%$. At the micro-level, the impact of SAPs was not as positive. The prescribed cutbacks on education, health, and welfare expenditure had significant implications on the health and livelihoods of many Ghanaians and especially the rural poor. This was compounded by public service downsizing, which saw the retrenchment of more than 300,000 public sector workers. Hardship and poverty characterized everyday life for many Ghanaians. One visible impact of these trends on the demography and health status of Accra was increased migration of individuals from the country's three northern regions and impoverished regions of the south, such as the Central and Volta regions, to the southern urban cities of Accra, Kumasi, and Takoradi. A large proportion of rural migrants, especially those from the north, settled in slum and squatter settlements. These settlements were often built on areas reserved for schools, institutions, and other public services, as well on water courses. They were of poor quality, overcrowded, and unsanitary. The Accra Metropolitan Assembly (AMA), successor to the Accra Town Council of the early twentieth century, struggled to maintain sanitary conditions in the city. Addae ${ }^{3}$ discusses a number of challenges that faced the AMA and the city in the 1980s and 1990s: "building regulation and control was in a state of total paralysis and collapse"; "drain construction was extraordinarily slow"; refuse generation by an expanding population generated large amounts of refuse that became difficult to collect and dispose of; and an increasing number of inhabitants of Accra, 
particularly in poor areas, lacked access to potable water. Thus, environmental degradation, poor sanitation and lack of safe drinking water contributed significantly to diseases especially among Accra's poor communities.

The late 1990s marked a transition in government. The ruling NDC government lost democratic elections to the opposition NPP party led by John A. Kufour. Kufour's government inherited the development policies of the previous government and continued to be significantly reliant on foreign aid. However, the emphasis of international developments policies shifted, subtly, from "economic growth" to "poverty reduction." The World Bank and IMF project of relieving debt for Heavily Indebted Poor Countries (HIPC) constituted a key model within this poverty reduction strategy. Amidst much public debate, the government signed Ghana up to HIPC status and received a comprehensive debt reduction package in 2002. ${ }^{38}$ Between 2000 and 2008, a variety of international community-led initiatives were introduced, including debt cancellation from the G8 and the Millennium Challenge account, spearheaded by the US government. These initiatives aimed to reduce poverty and improve livelihoods of people in poor countries. As a poster country for the success of the SAPs in 1980s Africa, ${ }^{37}$ and through the NPP government's active courting of foreign partnership and aid in development, Ghana became an integral part of this new global economic order.

The macrolevel successes of the SAPs in the 1980s and 1990s and the poverty reduction schemes of the 2000s have transformed Accra into a modern global city and the vibrant hub of Ghana's post-adjustment economic, social, and political life. Foreign investment has increased since the late 1980s. In 1988, the Accor Group of Hotels built the first multinational hotel, Novotel, in Accra. Other foreign investors followed suit and invested in hotels, gated communities, and luxury apartments, often built on state lands in old desirable residential areas such as Ridge and Cantonments and in emerging nouveau-riche areas such as East Legon and East Airport.

Technological and industrial markers of globalization followed. Multimillion dollar mobile telecommunications and entertainment industries, for example, Scancom (MTN), Millicom (Tigo), and DSTV, a South African television broadcaster, settled in Ghana. Multinational companies established during Ghana's colonial era, such as Unilever (formerly UAC), and newer companies, such as Nestle, also expanded their institutional fortunes. Information technology outsourcing, already a multibillion dollar business in Asian and Latin American countries, was introduced. $^{39}$ China made inroads with trade and construction. ${ }^{40}$ And as the complex of international health and development communities grew, their representation in Ghana intensified. Thus, development partners such as USAID, DANIDA, GTZ, DFID, and the World Bank have established a strong institutional presence. By the year 2000, 665 companies from 80 countries had settled in Accra. ${ }^{40}$ The majority of multinational businesses and organizations attracted educated and skilled Ghanaians and expatriate Africans and Euro-Americans into its middle and senior management streams, creating a visible group of wealthy, cosmopolitan consumers of Accra's global products. The most recent chapter to Accra's transformation into a global city was the discovery of oil in Ghana's Western Region in 2007 and the influx of international oil and gas companies to the country and their expatriate employees to Accra.

Food is the final face of globalization in Accra. Accra has been an international food hub since the independence era. The city boasts a large number of international 
restaurants serving West African, Indian, Chinese, Lebanese, Vietnamese, Thai, Italian, and French cuisine; some restaurants were established in the 1960s." An Americanstyle fast-food industry has taken root more recently. This had beginnings in fast-food served by hotels and at supermarket delis in the 1970s. These early fast-food services catered largely to the middle and elite classes. In the early 1990s, Papaye restaurant introduced fast-food culture to a broader clientele. Located on Cantonments Roadrenamed "Oxford Street" after London's famous shopping street-and serving ubiquitous hamburgers and Coca-Cola, as well as "Ghanaianised" meals such as fried rice and chicken with local pepper sauces, Papaye fast became the hub of evening and weekend social meetings, particularly among youths and the working classes. Papaye's success encouraged a fast-food boom in Accra. Today, fast-food places range from services modeled on Papaye to international franchises such as Nandos and Bonjour (On the Run). These restaurants are usually located in wealthy neighborhoods, shopping districts and malls, and at gas stations, and they tend to serve up-market clientele. Cheaper kiosk versions of fast food-termed check check-usually located within markets, truck stations, and along Accra's busy roads, make brisk business with the less wealthy. American style fast-food restaurants coexist with restaurants serving affordable, traditional Ghanaian meals to a growing workforce that lives too far away in Accra's outlying suburbs to eat lunch at home. Both American-style fastfoods and Ghanaian traditional meals can be unhealthy, with high levels of sugar, salt and saturated fats, often consumed with high sugar content sodas, or "minerals" in Ghanaian parlance. ${ }^{41}$ Recent evidence suggests that individuals across the country are spending significant proportions of their monthly budgets on out-of-home breakfasts and lunches; Accra's expenditure constitutes the largest proportion of the national expenditure. ${ }^{41}$ Similarly, there is an emerging trend of individuals working late or hanging out at after-work bars to beat the heavy evening traffic; these practices are implicated in late eating and increased alcohol intake, and by extension increased chronic disease risks. ${ }^{41}$

It is important to note the role of structural factors in changing sociocultural food and dietary practices in the city. The trade liberalization ethos of Structural Adjustment and Poverty Reduction eras introduced changes in Ghana's food production and supply policies. Before 2000, the IMF and World Bank encouraged poor countries like Ghana to prioritize export-oriented growth, such as the production of cash crops for export. ${ }^{42}$ This led to less emphasis on production of basic food crops for local consumption and increased dependence on importation of these food items. Another effect of trade liberalization in the last decade has been the pressure placed on low-income countries to abolish subsidies for their farmers while rich countries have retained farming subsidies. This has led to the artificial inflation of some international food prices while putting food production in poorer countries out of business. For example, in 2003, Ghana attempted to raise import tariffs on poultry imports from the EU. The IMF pressurized the Ghanaian government to reverse the decision, which led to the demise of the local poultry industry. These developments have been compounded by aggressive marketing of energy-dense, processed foods (e.g., soft drinks, cooking oils, dairy products, and flour- and fatbased snacks) by multinational food companies-buoyed by thriving fast-food

\footnotetext{
"In Osu, the popular shopping district, there are at least four Chinese restaurants, four Indian restaurants, two Thai/Vietnamese restaurants, one Irish Pub serving Irish beer and food, seven major fast food outlets serving American-style fast food, and at least four Ghanaian restaurants.
} 
industries-in low-income countries. In Ghana and other West African countries, food consumption patterns have changed from traditional diets high in locally produced coarse grains, such as millet and sorghum, to modern diets high in imported wheat and rice, due largely to the interplay of structural factors outlined. ${ }^{42,43}$ African cities, like Accra, are the hardest hit by these food policy dynamics, particularly as their populations are largely consumers and not producers of local and foreign foods.

Public Health and the Burden of Disease How have these political, socioeconomic and demographic arrangements affected the health of Accra's inhabitants? Health researchers record three trends in Accra's disease profile: (1) the persistence of communicable diseases as major causes of disability and death, particularly among poor communities; (2) the increasing prevalence of noncommunicable diseases and their impact on morbidity and mortality particularly among wealthy communities; and (3) the arrival and increased impact of the HIV/AIDS epidemic. A fourth trend that has recently received attention, but limited empirical research, is the impact of environmental pollution, and especially e-waste, on the health of slum and poor communities. $^{44,45}$

Outpatient statistics for Accra for the period spanning 1987 and 1993 show that malaria, diarrhea, parasitic infections, and respiratory infections were among the top ten conditions presented at health centers. Communicable diseases like measles, whooping cough, and tetanus were not among the top ten causes of outpatient morbidity. Possible reasons may be that immunization services introduced in the late postcolonial period had been successful and had led to considerable reduction in these conditions. The major causes of death in post-adjustment Accra were no longer parasitic and infectious diseases as was the case in the 1950s and 1960s. At the beginning of the 1990s, circulatory diseases were the major causes of death. ${ }^{8}$ Twenty-six percent of all male deaths and $24 \%$ of all female deaths were due to circulatory diseases. Crucially, poor communities were affected by both communicable and circulatory diseases. ${ }^{8}$ This reflects the regional evidence of "the double jeopardy of infectious and chronic diseases" 12 experienced by poor communities and supports the "epidemiological polarization" element of the protracted polarized model.

Following the 1970s trend, the chronic disease burden has increased exponentially during the post-adjustment period. Epidemiological studies show increased prevalence of chronic diseases such as hypertension and diabetes, and increased mortality from these conditions across the country. ${ }^{46,47}$ Greater Accra Region bears a significant burden of the country's chronic disease problem. Prevalence rates of hypertension in Accra, for example, exceed the national prevalence and the prevalence rates recorded in other major cities such as Kumasi and Takoradi. ${ }^{48}$ Obesity levels in Ghana increased 2.5-fold between 1993 and 2003: from 10\% to $25.3 \% .{ }^{49}$ In 2003, Greater Accra Region had the highest obesity prevalence rates at $45.3 \%$. Child obesity is an emerging problem in Accra, especially among the middle and elite classes. ${ }^{50}$

Within Accra, key differences in health profile across wealth and gender have been reported. The trends reported in the Mamprobi studies of the 1970s persist to the present day with wealthier educated groups constituting high-risk groups for obesity, hypertension, and diabetes. Studies on hypertension show that prevalence rates within the civil service and other urban workplaces exceed rates among the urban and periurban poor. ${ }^{46}$ The chronic disease burden affects women and men 
differently. Women constitute high-risk groups for obesity. ${ }^{51,52}$ Hypertension and stroke rates are higher in men, ${ }^{47}$ although hypertension was the leading cause of maternal deaths in the Korle Bu Teaching Hospital in the 1980s and 1990s ${ }^{53}$ and is the current leading cause of maternal deaths nationally. ${ }^{54}$

The emergence of the HIV/AIDS pandemic during Accra's post-adjustment period has received great attention. The city of Accra has three sentinel sites for assessing the magnitude of HIV infection: Adabraka, Maamobi, and Korle Bu. The prevalence rates recorded at these sites have been low compared to national rates. The 2002 sentinel report indicated that the rate for Korle Bu was 2.2, Adabraka was 4.0, and for Maamobi 4.2. The summary measure for Accra was approximately $3.5 \%$; this was close to the median for the country at $3.4 \%{ }^{55}$ The sentinel figures contrasted sharply with other sites such as Agomanya (7.0), Koforidua (8.5), Tema (6.5), and Eikwe (6.0). One of the reasons cited for Greater Accra Region's low HIV prevalence is the high literacy of the populace. ${ }^{* 56}$ A common assumption is that a (health) literate population is more likely to adopt preventive sexual health practices. However, the preliminary results of the Accra Women's Health Study show that HIV-positive results significantly correlated with unprotected sexual intercourse and lifetime number of partners, suggesting that, in spite of widespread HIV/AIDS education campaigns, individuals still engage in unprotected sexual intercourse. ${ }^{10}$ Five years later, the 2007 sentinel report showed that the HIV prevalence decreased in Adabraka (3.4) and remained unchanged for Maamobi (4.2), but increased in Korle Bu (4.0). ${ }^{57}$ The summary measure for Accra was 3.4\%, which was higher than the median for the country at $2.6 \% .^{57}$

E-waste-a collective name for electronic devices dumped as waste-consists of toxic materials like plastics, lead, aluminum and silica that are implicated in serious conditions like cancer of the lymph system, central nervous system damage, asthma, and silicosis, respectively. Research suggests that Abglogbloshie, a slum area in Accra, has become a key destination for e-waste from Europe and America. ${ }^{4,45}$ These communities are exposed to e-waste through direct contact with toxic materials (for subgroups whose livelihoods depend on the toxic but valuable byproducts of e-waste) and through breathing in toxic fumes (for everyone else living in close proximity to dump sites). The full health implications are yet to be systematically researched.

Recent analyses of causes of death in Accra from the births and deaths registry show that in 2001, circulatory diseases were the major causes of death, followed by infectious and communicable diseases, diseases of the respiratory system, neoplasms, and injury and poisoning. There have been no systematic analyses of causes of death since 2001. However, piecemeal evidence from chronic disease research suggests that by 2003, two chronic diseases become top ten causes of death in the Greater Accra Region: stroke at number two, hypertension at number six. ${ }^{31}$ In 2007 , the Greater Accra regional director of health services announced that hypertension was the second cause of death in Accra. ${ }^{58}$ These data are likely to affect post-2001 mortality trends.

\section{DISCUSSION AND CONCLUSIONS}

In this paper we have described epidemiological changes in colonial, postindependence and post-adjustment Accra as an important first step towards deeper

\footnotetext{
*The national literacy rates are $66.4 \%$ for men and $49.8 \%$ for women $\left(\mathrm{UNESCO}^{56}\right.$ ).
} 
analysis of the causes and consequences of these changes for specific communities and of their implications for Accra's future health status. Accra's epidemiological change fits the protracted polarized model proposed by Frenk et al., ${ }^{13}$ with a protracted coexistence of infectious and chronic diseases as significant causes of morbidity and mortality, and polarized impact of the double burden of disease across socioeconomic status. The coexistence of infectious and chronic diseases had been evident since the establishment of specialist health services in the 1920s, but gained greater visibility and public health importance in the 1960s as institutional records on morbidity and mortality became more readily available. The 1980s saw the reemergence of epidemics such as small pox, which had been almost eradicated in the independence era. These epidemics were linked to increased migration and the establishment of crowded, unsanitary slum settlements. Epidemics of acute infectious diseases and the emergence of HIV/AIDS occurred alongside the rising prevalence of chronic diseases such as hypertension and diabetes. Research since the 1970s shows that wealthy populations face higher risks of chronic diseases and poor communities face higher risks of infectious diseases as well as the "double jeopardy" of infectious and chronic diseases.

We have identified three key factors underpinning the protracted polarized model of epidemiological transition in Accra: urbanization, urban poverty, and globalization.

Urbanization and urban poverty are intricately linked. Accra's population increased from 18,574 in 1911 to 1.7 million in 2000: a 90-fold increase in less than a hundred years. Population growth can be attributed to increasing migration, especially from poor Northern, Central, and Volta regions. Population expansion has had implications on sanitation and environmental health. Poor sanitation and environmental health are implicated in occasional outbreaks of infectious diseases, which affect poor communities disproportionately. Fundamentally, the health status of rural migrants and the urban poor embodies the "epidemiological polarization" element of the protracted polarized model. These groups are at risk of living with and dying prematurely from both acute infectious and chronic noncommunicable diseases. Risk manifests itself in terms of the intricate biological relationships between infectious and chronic diseases that thrive within the contexts of environmental degradation, poor sanitation, and overcrowding, as well as in poor lifestyles. The rising prevalence of HIV/AIDS in poor areas of Accra also raise the issue of HIV/AIDS morbidity, disability, and death, as well as the risk of rising prevalence of cardiovascular diseases and diabetes through ART. Rapid urbanization and the public health threats it brings has placed a huge burden on health services. Accra contains a vast number of public and private health facilities including the nation's premier medical school and teaching hospital. However, access to care is inadequate for poor communities and quality of care is poor for all social groups, particularly for chronic conditions. This leads to avoidable morbidity, disability, and deaths.

Globalization is often defined in terms of its multiple impacts on economies, technology, culture and, increasingly, ecology. Our review suggests that, since the independence era, Accra has experienced this multiple impact of globalization. The economic and industrial impact is evident in the changes to living and work arrangements for many Accra inhabitants. As Accra has expanded its residential boundaries and maintained its business districts at the center, distances between work and home have increased for a growing number of people. Former patterns of family life and health-related lifestyles, such as sharing meals at home, have changed. Research evidence on increased consumption of out-of-home meals in 
Accra provides concrete evidence for this structurally mediated lifestyle shift. These concrete changes in lifestyle patterns are implicated in the rising prevalence of lifestyle diseases and their risk factors such as hypertension, diabetes and obesity. ${ }^{41,51}$

Globalization has also had a cultural impact. For many communities in Accrawealthy or poor-group and individual preferences for Western cultural products, such as foods, technology and language have deepened. The changing preferences for food in particular can be partially attributed to food policies of the structural adjustment and poverty reduction eras. Research suggests the nutrition transition and the rise in technology-aided, sedentary lifestyles (cars, computers at home and in internet cafes, games consoles for elite and middle class youth) are strongly implicated in Ghana's obesity and chronic disease epidemics. This complex relationship between globalization and public health has been reported in other African cities such as Banjul, ${ }^{59}$ Yaounde, ${ }^{60}$ and Dar es Salaam. ${ }^{61}$

The ecological impact of globalization has emerged more recently. The technological products of globalization-computers, television sets, mobile phones-have become sources of environmental pollution and disease for some poor communities in Accra. ${ }^{44,45}$ Research suggests similar trends in West African cities.

The factors underpinning Accra's epidemiological transition, particularly since the post-adjustment years, are unlikely to change imminently. Rural-urban migration continues to rise, the population of Accra continues to grow, and globalization processes continue to intensify. Ghana's health sector, like that of many African countries, is ill-equipped to deal with the country's double burden of disease. While policy-makers recognize a double burden of disease, a significant percentage of the health budget continues to be allocated to infectious diseases and to the rising challenges of HIV/AIDS. ${ }^{32}$ For Accra, which bears a significant proportion of the country's double burden of disease, this lack of concrete health sector intervention has important implications including weakened health systems, health-illiterate communities, increased household burden of disease, and a vicious cycle of poverty and disease.

More research is needed to understand the role of population increase and urbanization on disease patterns and on microsocial processes such the interrelationship between changing lifestyles, diet, and overnutrition across all social classes. It is important that future research addresses the issue of comorbidities and treats communicable and noncommunicable diseases as potentially interrelated and mutually reinforcing. ${ }^{4,20}$ This approach will facilitate deeper understanding of the relationship between environment, biology, and health to address the problem of why poor communities in Accra experience the "double jeopardy" of infectious and chronic diseases. It will be important to examine the complex demands of contemporary culture, work, and family systems to understand the burden of stroke in men and the burden of obesity and obesity-related conditions among women. Nuanced understandings will inform the development of target-specific preventive and curative interventions to address Accra's "protracted" double burden of disease and its "polarized" impact across socioeconomic status.

Few case studies of epidemiological transition in African cities exist. However, the insights from Accra with respect to a protracted polarized model of epidemiological transition are likely to apply to other African cities given the similarities in demographic and health profiles: rapidly aging populations, rural-urban migration, rapid urbanization, urban poverty, globalization, a burgeoning middle and elite class, and a double burden of chronic and infectious diseases. The available data on the nutrition transition in Banjul, ${ }^{59}$ Yaounde, ${ }^{60}$ and Dar es Salaam ${ }^{61}$ support this position. 
Emerging research on the double burden of disease within slum communities in Kenya also offer useful insights in this area. ${ }^{62}$ However, more systematic analyses of demographic and mortality data across African countries-along the lines of the study by Kahn et al. ${ }^{21}$-are required to build a robust case for a protracted polarized model of epidemiological transition in African cities and to develop the appropriate contextspecific interventions.

\section{ACKNOWLEDGEMENTS}

Earlier versions of this paper were presented at the Seminar on Health in African Cities, Harvard Center for Population Studies, Harvard University (2004), and at the Union of African Population Studies conference (2007), and benefited from critical comments made by participants.

\section{REFERENCES}

1. Omran AR. The epidemiological transition theory: a theory of the epidemiology of population change. Milbank Mem Fund Q. 1971; 49: 6-47.

2. Patterson K. Health in urban Ghana: the case of Accra, 1900-1940. Soc Sci Med. 1979; 13B: $251-268$.

3. Addae S. History of western medicine in Ghana, 1880-1960. Durham: Durham Academic Press; 1996.

4. Pobee JOM. The heart of the matter. Community profile of cardiovascular diseases of a sub-Saharan African country. Accra: Commercial Associates Ltd; 2006.

5. Field MJ. Religion and medicine of the Ga people. Oxford University Press; 1961.

6. Acquah I. Accra survey. London: University of London Press; 1958.

7. Robertson C. Sharing the same bowl: a socioeconomic history of women and class in Accra, Ghana. Bloomington: Indiana University Press; 1984.

8. Stephens C, Timaeus I, Akerman M, et al. Environment and bealth in developing countries: an analysis of intra-urban differentials using existing data. London school of hygiene and tropical medicine. Republic of Ghana: Fundacao Seade; 1994.

9. Songsore J, McGranahan G. The political economy of household environmental management: gender, environment and epidemiology in the Greater Accra Metropolitan Area. World Dev. 1998; 26(3): 395-412.

10. Hill AG, Anarfi JK, Darko R, Duda B. Self-reported and independently assessed measures of population health compared: results from the Accra Women's Health Survey. Paper presented at the IUSSP General Conference, France, 21st July 2005.

11. Applin G, Beggs P, Brierley G, et al. Global environmental crises: an Australian perspective. Oxford University Press; 1999.

12. Smallman-Raynor M, Phillips D. Late stages of epidemiological transition: health status in the developed world. Health Place. 1999; 5(3): 209-222.

13. Frenk J, Bobadilla JL, Sepulveda J, Cervantes ML. Health transition in middle-income countries: new challenges for health care. Health Policy Plan. 1989; 4(1): 29-39.

14. Jones K, Moon G. Medical geography: global perspectives. Prog Hum Geogr. 1992; 16 (4): 563-572.

15. Landers J. Introduction: historical epidemiology and the health transition. Health Transit Rev. 1992; 2(suppl): 1-27.

16. Jamison DT, Feachem RG, Makgoba MW, et al., eds. Disease and mortality in SubSaharan Africa. 2nd ed. Washington: The World Bank; 2006.

17. Cooper RS, Rotomi CN, Kaufman JS, Muna WFT, Mensah GA. Hypertension treatment and control in sub-Saharan Africa: the epidemiological basis for policy. BMJ. 1998; 316: 614-617. 
18. Unwin N, Setel P, Rashid S, et al. Noncommunicable diseases in sub-Saharan Africa: where do they feature in the health research agenda? Bull World Health Organ. 2001; 79 (10): 947-953.

19. Young F, Critchley JA, Johnstone LK, Unwin NC. A review of co-morbidity between infectious and chronic disease in sub-Saharan Africa: TB and diabetes mellitis, HIV and metabolic syndrome, and the impact of globalization. Global Health. 2009; 5: 9.

20. Unwin N, Alberti KGMM. Chronic non-communicable diseases. Ann Trop Med Parasitol. 2006; 100(5 \& 6): 455-464.

21. Kahn K, Garenne ML, Collinson MA, Tollman SM. Mortality trends in a new South Africa: hard to make a fresh start. Scand J Public Health. 2007; 35(S69): 26-34.

22. Alhassan O. Land use and environment in early Accra (1300 to 1800 AD). Research Review Suppl. 2006; 17: 21-36.

23. van Dantzig A. Forts and castles of Ghana. Accra: Sedco Publishing Limited; 1980.

24. Kea RA. Settlements, trade, and politics in 17th century gold coast. Baltimore and London: Johns Hopkins University; 1982.

25. Akyeampong EK. Slave Routes, Slave Roots and Nation-Building: Ghana, Ghanaians Abroad and the African Diaspora in the 21st Century. Inaugural Lecture, Launch of the International Institute for the Advanced Study of Cultures, Institutions and Economic Enterprise, International Conference Center in Accra, 21st August 2007.

26. Simpson WJR. Report on plague in the gold coast, 1908. London: J \&A Churchill; 1909.

27. Lisowska J. The demographic, social and professional structure of Accra between 1960 and 1970. Afr Bull. 1984; 32: 113-129.

28. Domfeh KA. Some environmental factors affecting health in the Greater Accra Metropolitan Area. Environments. 1999; 27: 1-13.

29. Akyeampong EK. Towns, town life, and disease in colonial West Africa. Legon J Humanities. 2006; Vol. XVII: 25-43.

30. Agyei-Mensah, S. Epidemiological transition and the double burden of disease in Accra, Ghana. Paper presented at the 1st Annual Workshop, UK-Africa Academic Partnership on Chronic Disease, Noguchi Memorial Institute for Medical Research, Accra. 12th April 2007.

31. Bosu WK. Ghana's National NCD Programme: history, prospects and challenges. Paper presented at the 1st Annual Workshop, UK-Africa Academic Partnership on Chronic Disease, Noguchi Memorial Institute for Medical Research, Accra. 12th April 2007.

32. de-Graft Aikins A. Ghana's neglected chronic disease epidemic: a developmental challenge. Ghana Med J. 2007; 14(4): 154-159.

33. Amanor B, Martinson V. Is hypertension increasing in Ghana? Ghana Med J. 1969; 8: 279-280.

34. Haddock DRW. Cerebrovascular accidents in Ghana. Trans Roy Soc Trop Med Hyg. 1970; 64: 300-310.

35. Aidoo M. Some of the types of breast diseases at Korle Bu hospital during the period 1968-71 with emphasis on breast cancer-a preliminary study. Ghana Med J. 1973; 12: 233-236.

36. Anim JT, Laing WN. Cancer of the cervix - a review of surgical material at the Korle Bu teaching hospital, Accra for the years 1966-1970. Ghana Med J. 1972; 11: 118-121.

37. Konadu-Agyemang K. The best of times and the worst of times: structural adjustment programs and uneven development in Africa: the case of Ghana. Prof Geogr. 2000; 52(3): 469-483.

38. GhanaWeb. Ghana to Receive $\$ 3.7$ Billion in Debt Service Relief. 2002. Available at: http://www.ghanaweb.com/GhanaHomePage/NewsArchive/artikel.php?ID=22059. Accessed August 16, 2010.

39. Zachary GP. Black Star: Ghana, information technology and development in Africa. First Monday. 2004; 9(3). Available at: http://firstmonday.org/issues/issues9_3/zachary/index. html. Accessed August 16, 2010. 
40. Grant R. Liberalisation policies and foreign companies in Accra, Ghana. Environ Plan. 2001; 33: 997-1014.

41. de-Graft Aikins A. Eating, drinking and smoking habits in Ghana: a public health psychology perspective. Invited Lecture, West African College of Physicians (WACP)/ Ghana College of Physicians and Surgeons, (GCPS) Cardiology Update Course, GCPS, Accra. 6th June 2007.

42. Lock K, Stuckler D, Charlesworth K, McKee M. Potential causes and health effects of rising global food prices. BMJ. 2009; 339: b.2403.

43. Teklu T. Food demands studies in sub-Saharan Africa: a survey of empirical evidence. Food Policy. 1996; 21: 479-496.

44. Brigden K, Labunska I, Santillo D. Chemical contamination at electrical and electronic waste recycling and disposal sites in Accra and Koforidua, Ghana. Greenpeace Research Laboratories Technical Note 10/2008, 2008.

45. Oteng-Ababio M. E-waste: an emerging challenge to solid waste management in Ghana. Int Dev Plann Rev. 2010; 32(2): 191-206.

46. Addo J, Smeeth L, Leon DA. Prevalence, detection, management, and control of hypertension in Ghanaian civil servants. Ethn Dis. 2008; 18: 505-511.

47. Amoah AGB, Owusu KO, Adjei S. Diabetes in Ghana: a community prevalence study in Greater Accra. Diab Res Clin Pract. 2002; 56: 197-205.

48. Agyemang C, Bruijnzeels MA, Owusu-Dabo E. Factors associated with hypertension awareness, treatment, and control in Ghana, West Africa. J Hum Hypertens. 2006; 20: 67-71.

49. Ghana Statistical Service (GSS). Noguchi Memorial Institute for Medical Research (NMIMR), and ORC Macro. Ghana Demographic and Health Survey 2003. Calverton: GSS, NMIMR, and ORC Macro; 2004.

50. Mohammed H, Vuvor F. Prevalence of obesity in University of Ghana primary school. Paper presented at the First Annual Scientific Conference of the College of Health Sciences, University of Ghana, Accra, September 2007.

51. Amoah AGB. Sociodemographic variations in obesity among Ghanaian adults. Public Health Nutr. 2003; 6(8): 751-775.

52. Biritwum RB, Gyapong J, Mensah G. The epidemiology of obesity in Ghana. Ghana Med J. 2005; 39(3): 82-85.

53. Lassey AT, Wilson JB. Trends in maternal mortality in Korle Bu Hospital, 1984-1994. Ghana Med J. 1998; 32a: 910-916.

54. Kumi-Aboagye P. Status of MDG 5-evidence from the field. Paper presented at the National Consultative Meeting on the Reduction of Maternal Mortality in Ghana. Accra. 8th July 2008.

55. National AIDS/STI Control Programme/Ghana Health Service. HIV sentinel survey report 2002. Accra: NACP/GHS; 2003.

56. UNESCO. Country profile: Ghana. Montreal: UNESCO Institute for Statistics; 2006.

57. National AIDS/STI Control Programme/Ghana Health Service. HIV sentinel survey report 2007. Accra: NACP/GHS; 2008.

58. Yeboah LA. Hypertension ranks second in Greater Accra. Daily Graphic. 2007, p. 43.

59. Prentice AM. The emerging epidemic of obesity in developing countries. Int J Epidemiol. 2006; 35: 93-99.

60. Sobngwi E, Mbanya J-CN, Unwin NC. Physical activity and its relationship with obesity, hypertension and diabetes in urban and rural Cameroon. Int J Obes. 2002; 26: 10091016.

61. Maletnlema TN. A Tanzanian perspective on the nutrition transition and its implications for health. Public Health Nutr. 2002; 5(1A): 163-168.

62. Kyobutungi C, Ziraba AK, Ezeh A, Ye Y. The burden of disease profiles of residents in Nairobi slums: results from a demographic surveillance system. Population Health Metrics. 2008; (6): 1 